\title{
TEORIA POLÍTICA CLÁSSICA: RAMIFICAÇÕES DE GRÉCIA E ROMA
}

\author{
Patricio Tierno \\ é professor de Teoria Política do Departamento de Ciência Política da \\ Universidade de São Paulo \\ E-mail:<ptierno@usp.br> \\ Orcid: 0000-0001-7543-8195 \\ http://dx.doi.org/10.1590/0102-015029/107
}

Deixo aos vários porvires (não a todos) meu jardim de caminhos que se bifurcam.

Jorge Luis Borges, FiCÇÕES

À semelhança daquele labirinto oriental da literatura, escrito imaginário de símbolos e de tempos (Borges, 1963), o universo da teoria política clássica (deveríamos dizer: o universo, para o pensamento antigo em geral) tem sido construído por várias séries temporais, bifurcações e ciclos, pontos de partida para ulteriores séries convergentes e divergentes, que recomeçam em círculo ou são habitadas em paralelo. Ou quiçá, com maior precisão, o pensamento político clássico, ubíquo e estranho, corresponde-se com a metáfora vegetal que mais recentemente lhe fora adjudicada (Balot, 2009b, p. 6), uma árvore transplantada desde suas raízes a nosso ambiente, saudável, ramificada e copiosa, e ainda mais alheia. Em qualquer caso, essas possibilidades, linhas que se aproximam ou se fecham, interrompendo-se 
ou ignorando-se, e também a recuperação de algumas dessas possibilidades, representam fragmentos de um mundo humano, histórico e intelectual, que temos recebido e herdado. O Dossiê que aqui se apresenta vem a somar-se, a título de iniciação, à recepção, recuperação e reflexão em torno da teoria política da antiguidade clássica.

A delimitação do período coberto não carece de importância. Com efeito, a teoria política clássica compreende o período situado entre a última década do século VI a.C. e o terço final do século V d.C., abarcando, nesse decurso variado, as singulares e conexas experiências que tiveram seu centro no mundo grego e romano. Dois eventos, de um modo algo arbitrário, marcam a duração convencional da antiguidade clássica na Grécia e em Roma: o estabelecimento da constituição democrática de Clístenes em Atenas (508-7 a.C.) e a destituição de Rómulo Augusto, último imperador romano do Ocidente (475-6 d.C.). Ao longo do período, que não 16 pode ser visto como temporalmente uniforme nem espacialmente homogêneo, desenvolveu-se um rico corpus de ideias e modos de pensamento político, toda uma literatura de gêneros e registros diversos, em suma, teorias, discursos, vocabulários e conceitos concernentes ao político e, portanto, a determinada consciência de vida política, cuja caracterização adequada exige dirimir sua nominação específica, seus traços particulares e, talvez, seu propósito comum. Mediante essa tarefa clarificadora será possível, por fim, conceder um sentido próprio e extensivo às estimulantes e originais contribuições que este volume oferece ao leitor.

Um denominador capaz de assimilar aquele corpo intelectual e as realidades históricas sobre as que a inteligência greco-romana se debruçara nos tempos antigos se mostrará fundamental. Até agora, as tentativas ensaiadas terminaram por fazer da demarcação dos distritos disciplinares um conjunto esquemático e compartimentado, fragilizado por divisões supérfluas, que pouco ajudam no uso de uma terminologia sempre 
alimentada por significações lábeis, que admitem equivalências na mesma medida que resistem à fixação. ${ }^{1}$ Assim, tanto o pensamento quanto a filosofia e a teoria política definem um vasto campo de reflexão constituído por níveis de sistematização e meios de escrita e oralidade, o que levou a tradição clássica a concretizar-se numa literatura de vária composição. ${ }^{2}$ A esse respeito, a teoria política clássica, designação institucionalizada que nos convoca neste momento e que, de certa forma, privilegiamos, destaca-se precisamente por sua plasticidade e heterogeneidade constitutivas, sua modalidade prática, reflexiva e consciente e, por isso mesmo, sua função mediadora e unificadora do conhecimento do político e da política e das vias de acesso a suas manifestações plurais.

E nessa natureza composta da teoria política clássica descansa, ademais, sua vigência. Os entrelaçamentos temporais que ela carrega consigo têm sido a condição de possibilidade de sua recepção e de sua posterior apropriação, promovidas por aproximações metodológicas interdisciplinares, algumas vezes opostas ou excludentes, outras complementares ou sobrepostas, e inclusive indiferentes às fronteiras acadêmicas que separam a filosofia, a história e a literatura. Seja como for, além dos métodos de abordagem e tratamento que lhe são inerentes, a propedêutica de uma teoria política que tenha no centro gravitacional de seu interesse o clássico deve assumir como empresa prioritária a confecção de uma perspectiva preparada para reunir modelos teóricos tomados das ciências sociais e, em condições lógicas, vale dizer, prévias, de integrar nossa compreensão dos textos e autores antigos e fazer uso deles, como propositivamente

\footnotetext{
1 Pode-se constatar um esforço sumário por postular distinções entre o pensamento político, a filosofia política e a teoria política, desmentido a posteriori pela própria obra em razão de seu caráter misto, na introdução à coletânea de referência escrita por Rowe (2005, pp. 1-2).

2 Um exemplo, contrário ao citado, pode ser encontrado na heterodoxa proposta que, com relação à tragédia grega, fora introduzida (e organizada) por Euben (1986, esp. pp. 1-7 e n. 16).
} 
insiste o historiador da antiguidade Josiah Ober, de sorte a "representar algum aspecto do passado de uma maneira que seja significativa e útil" (Ober, 1999b, p. 15, cf. Ober, 1999b, pp. 13-17). ${ }^{3}$ Seguindo o guia desse paradigma de interpretação propiciador de sentidos hermenêuticos e valores heurísticos, cabe então enunciar a concatenação de pressupostos e ferramentas aos quais recorrer na leitura e na comparação das fontes antigas, em regra geral heterogêneas, confrontadas em cópias manuscritas e versões tardias, quando não em estado fragmentário ou parcial, mas em qualquer caso fruto de um processo de transmissão secular. De fato, será necessariamente a natureza metamorfoseada das fontes datadas o alicerce empírico de toda abordagem secundária e toda interpretação produtiva e plausível.

Em primeiro lugar, uma das constatações que mais se busca evidenciar na teoria política clássica reafirma a relação significativa entre, por um lado, comunidade política e regime político e, por outro, reflexão crítica. ${ }^{4}$ Por isso, apreender a dinâmica imperante nas comunidades antigas, o que equivale a captar a emergência e a consolidação de uma cultura dominante - com sua ideologia, seus valores em conflito, suas práticas comunitárias e sua organização institucional -, pondo-a em recíproco contraste com as formas da consciência coletiva e as manifestações intelectuais produzidas e que a reproduzem, erige-se num passo liminar iniludível.

Em segundo lugar, partindo da afirmação precedente, a teoria política clássica aspira logo a verificar, por meio

\footnotetext{
3 Para uma revisão crítica e abrangente das aproximações contemporâneas (não estritamente filosóficas) à política no mundo antigo, grego e romano, vide Hammer (2009).

4 Servindo de inspiração aos próximos parágrafos, cf. Ober (1998, esp. pp. 3-8; 1999e). Contudo, o delineamento de uma reflexão e consciência críticas, assim como o período considerado neste Dossiê, é mais amplo que o sentido historicamente circunscrito e a leitura enviesada que o autor aplica à seleção de textos da elite dissidente de Atenas e sua crítica da democracia em finais do século V e durante grande parte do século IV a.C.
} 
da modelação reconstrutiva de imagens e subjetividades desse distante passado, a utilidade e relevância do pensamento e da literatura antiga na ótica da moderna contemporaneidade. Não obstante, essa relevância prática, exposta na teoria, não parece clara nem direta, razão pela qual "são necessários argumentos com o intuito de mostrar que o pensamento político clássico é significativo, útil e interessante para a modernidade" (Balot, 2009b, p. 15), em sintonia com o aviso que o filósofo Bernard Williams, demandante da atualidade do pensamento e a literatura gregas, deixara-nos como encargo nada óbvio e nunca dado (Balot, 2009b, p. 15, e, sobre as implicações da postura de Williams, Balot, 2009b, pp. 15-17).

Já no plano das instâncias interpretativas, pretende-se entender e explicar, em terceiro lugar, quais foram e de que modo se deram as condições lógicas e de possibilidade para a geração e inserção do pensamento político antigo no marco de comunidades evolutiva e socialmente complexas, de existência mantida durante longo tempo graças a suas capacidades materiais, políticas e culturais de expansão elevada, reprodutoras de um estado social diferenciado e movidas por uma dinâmica conflituosa (cf. Ober, 1998, p. 4; 1999a, p. 5; 1999c; 1999d; 1999e, esp. pp. 140-145). Nesse meio social de tensões constantes, chegaram-se a instaurar, todavia, ordens legais com padrões avançados de adaptação e estabilidade política, enquanto se fixava uma hierarquia comunitária estratificada baseada na exclusão vertical de determinadas categorias humanas e, conforme se trate de um exemplo ou outro, uma cidadania com acesso igual à participação ou com direitos cívicos distribuídos proporcionalmente. ${ }^{5}$ Em último lugar, como quarta instância interpretativa, é mister decifrar, com

\footnotetext{
${ }^{5}$ Para uma visão comparativa que contempla Grécia e Roma, e a propósito do traço de igualdade ou gradação hierárquica que diferenciava a democracia grega e a república romana, cf. Hammer (2015, esp. pp. 2 e ss.); Konstan (2015); Farenga (2015); Schofield (2015); Rhodes (2015); Mouritsen (2015).
} 
o maior grau de esclarecimento, o locus e o status da teoria política clássica ou, em outras palavras, prover o estudo da teoria política clássica de uma conceituação que a ilumine enquanto fenômeno situado em seu tempo e por seu caráter. Dessa perspectiva, parece exequível apelar a noções que possam descrever os fenômenos históricos aludidos nos termos de seus próprios movimentos intelectuais, isto é, de grupos ou círculos relativamente seletos vinculados a e condicionados por certos modos de pensamento reflexivo, crítico e consciente. A natureza dessa descrição é, a rigor, instrumental: a reflexão assim entendida designa as formulações ou corpos mais ou menos sistemáticos de ideias cuja reconstrução permite identificar, a posteriori, uma teoria instituída sobre uma práxis singular e, por esse intermédio, a configuração de um gênero de pensamento fundado numa intervenção que porta um juízo e uma justificação, passível de ser tanto negativa quanto positiva (de refutação ou contestação, mas também 20 construtiva ou propositiva), e portanto orientadora da ação.

A chave de entrada no mundo antigo, comprimida numa aproximação que desdobra a tradição clássica de pensamento político greco-romano atribuindo-lhe, enquanto corpus de textos e autores inseridos nas coordenadas espaço-temporais anteriormente especificadas, a nota distintiva da crítica reflexiva, demarca, por sua própria compreensão, uma concepção do político, da esfera de atividades práticas e teóricas pertencente às coisas da cidade, que encontra seu núcleo problemático na investigação sobre a vida comum - a educação cívica e o exercício da virtude por parte dos cidadãos, a natureza e a determinação ética dos fins coletivos ou do bem humano geral -, e na interrogação em torno da experiência eminentemente política que os habitantes das comunidades antigas tiveram de si (cf. Balot, 2009b, pp. 9 e ss., 17-18; Hammer, 2009, pp. 34-35; Ober, 1999e, esp. pp. 146-148). Por certo, é o elenco de grandes autores e de autores menores, os textos díspares dados à publicidade 
junto às continuidades e rupturas que esses modos de pensar criaram e recriaram com relação ao arcabouço argumentativo e terminológico estabelecido pelo contexto comunitário de atuação, o fator que compõe as evidências de todo um vocabulário e um repertório de tópicos e perguntas provindos da interlocução de formas literárias e conteúdos discursivos. ${ }^{6}$ Nessa multiplicação de sentidos autoral e textual, em diálogo geracional com os contemporâneos e seus predecessores, projetando-se para um futuro ignorado, prefigura-se em cada ato de escritura uma significação maior: a redefinição constante da ordem e natureza humanas, da matriz de relações sociais e do pano de fundo cultural, operada por uma reconstrução que alinha a perspectiva da história intelectual do pensamento político antigo com os horizontes interpretativos do presente. A teoria política clássica não tem por função primordial mais do que compreender, naquela mesma perspectiva e nesse horizonte de épocas ou, para dizê-lo de uma maneira equiparável, a partir de situações reais inassimiláveis e estruturas conceituais herdadas, o complexo de ideias e de instituições que o passado conheceu na escala reduzida da cidade antiga e que hoje, uma vez surgido, desenvolvido e transmitido à modernidade tardia, edifica-se como o dificultoso legado da Grécia democrática e da Roma republicana. ${ }^{7}$

Cumpre, por conseguinte, ilustrar com as intervenções que põem em relevo as camadas temporais em razão das quais autores e textos representativos se tornam peças de leitura da época moderna. As contribuições que nosso Dossiê tem convocado podem ser, e talvez em boa hora sejam, mostras fiéis das mediações interpretativas em jogo na disputa pelo sentido de acontecimentos originados na democracia de Atenas do século

\footnotetext{
${ }^{6}$ Para um enfoque histórico-intelectual do pensamento político grego e romano centrado em autores, $v$. Rowe e Schofield, 2005.

7 Para uma edição alternativa que privilegia o tratamento temático e atualizado desse pensamento, vide Balot (2009a).
} 
V a.C. e na república de Roma no decorrer das últimas décadas do século II a.C. Essas mediações, provas de reconstrução e reinterpretação dos eventos e do discurso teórico-político, não só canalizam o exame de conjunto dos elementos analíticos antes enumerados, mas também, e em especial, realçam três dimensões sancionadas pelos protagonistas daqueles e destes tempos: as estruturas ideológica, econômica e social das práticas efetivas e simbólicas dos atores na captação sucessiva de três fragmentos da antiguidade helena e romana.

O pensamento conservador ainda ecoa essa espécie de diatribe que Platão lançara contra a democracia ateniense. Na sua República, em meio a interlocutores ávidos de saber extraídos da elite culta, o Sócrates platônico descarrega sobre o regime democrático toda a responsabilidade pela corrupção que, irrefreável, perpassa a comunidade. A democracia, forma de governo que decreta a igualdade indiferenciada após a vitória dos pobres sobre os ricos, é dona de uma 22 liberdade licenciosa, híbrida, ilegal e, por tudo isso, "prazerosa, anárquica e diversificada" (Rep. 558c) ${ }^{8} \mathrm{O}$ homem democrático, o isonomikós (561e), tipo psíquico do regime ao que lhe brinda apoio, é por simbiose governado pela luta interior de seus desejos, dissociado consequentemente de certezas firmes, caráter previsível e princípios sólidos reguladores de sua conduta. Estendendo o paralelismo, porque esse homem que forma o vulgo é incapaz de verdadeiro conhecimento, a pólis está, desde seu nascimento, perdida.

Mas a antítese socrático-platônica teve, mais de meio século antes, nos primórdios da guerra com Esparta, sua consagração no discurso de Péricles narrado por Tucídides (II, 34-46). Este, que se juramentou manter a objetividade da história, foi sempre crítico da democracia de Atenas, cujo démos, em sua opinião, não pudendo dissimular as contradições fáticas em que incorria

\footnotetext{
8 As traduções ao português das obras clássicas, no caso das edições em espanhol, têm sido modificadas por nós com base no grego original.
} 
com suas decisões, conduziu o regime a um franco declínio, já na fase pós-Péricles, da sua política interna e externa. Se alguma dimensão crucial nos revela o narrador, é precisamente aquela que, consistente na ligação entre os fatos crus (érga) e o poder (krátos, dýnamis), possui o discurso (lógos) por conta de seus efeitos retóricos e sua incidência nas ações (cf. Ober, 1999e, pp. 155-157; 1999c, pp. 20, 29-30). A reprodução estilizada da Oração Fúnebre pronunciada sob o sol do inverno pelo estratego ateniense em nome dos mortos durante o primeiro ano da contenda, num discurso modelar que inspiraria a melhor oratória democrática, encarna muito mais do que um mero elogio, pois entranha, segundo a incisiva escrita de Antonio Hermosa Andújar, uma antropologia da democracia e uma pintura do indivíduo democrático, plasmadas no ideário que motivava sua vida pública e privada. Desses traços antropológicos derivam, sustenta o autor do primeiro artigo deste Dossiê, um ser real e autônomo, um cidadão e um homem do cotidiano em que se perfila um tipo inédito de sujeito histórico em condições de fazer frente à trajetória coletiva da qual é parte e à consciência dessa mesma trajetória que o compromete.

Segue, em ordem de aparição, a nítida análise que uma das organizadoras de nosso Dossiê, Eunice Ostrensky, dedica à elucidação do dúbio posicionamento historiográfico adotado por Maquiavel diante do ocorrido em Roma entre 133 e 122 a.C. com motivo da lei agrária, as reformas dos irmãos Graco e, de acordo com o posterior ditame de Tito Lívio do qual se parte em Discursos I, 37, as consequências nocivas sofridas pela república. $\mathrm{O}$ artigo procura explorar, num primeiro plano, a justaposição entre antigas e novas convenções intelectuais. Embora repetidas vezes faça a apologia da imitação da antiguidade, Maquiavel ao mesmo tempo se apresenta como um inovador, alguém capaz de desbravar novas águas e terras e abrir novos caminhos (D I, "Prólogo"). Em sua narrativa sobre as leis agrárias, ainda que em grande parte se reproduza a versão tradicional dos antigos escritores 
romanos, vozes dissonantes são adicionadas e os leitores são convidados a examinar o caso em questão de uma distinta e perturbadora perspectiva, planejada para chacoalhar crenças e os levar, também a eles, a uma nova tomada de posição, o que sempre traz riscos. $\mathrm{O}$ novo emerge, assim, de uma imitação não servil do antigo. Num segundo plano, convergente com o primeiro, Maquiavel ousadamente reitera a tese de que a discórdia entre nobres e plebeus levou Roma à grandeza e à liberdade. Não fossem ordenações como as leis agrárias propostas pela plebe e seus delegados, Roma teria se arruinado muito antes. Ao mesmo tempo, porém, uma república imperialista inevitavelmente superaria esforços de contenção das ambições internas à cidade, levando-as a transbordarem na aquisição de territórios longínquos.

A riqueza subjacente a esse segundo artigo reside na sua postura fiel para com as variações narrativas absorvidas por Maquiavel, exemplo conatural ao julgamento dos fatos 24 históricos, e, simultaneamente, na explicação que a autora encontra do porquê dessa ambivalência, destacando o dispositivo retórico essencial à estrutura da argumentação. Além disso, submete-se à apreciação teórica uma faceta da corrente republicana que é recomendável nunca passar por alto, a saber, a decisiva estipulação das pré-condições econômicas a ser levada em conta e pensada nas fundações de toda república (cf. Gargarella, 1999, pp. 166-173; D I, 55). Por essa razão, poderia asseverar-se, com Cícero, fervente representante deste modo clássico de reflexão, que a preocupação pelos efeitos da posse de terras e o regime econômico sobre as formas de subjetivação da ordem política se remonta até às origens míticas da Roma monárquica, quando o sucessor de Rômulo, Numa Pompílio:

repartiu entre cada um dos concidadãos os campos que Rômulo tomara na guerra, ensinou-lhes que sem o ataque e a pilhagem eles poderiam abundar em todas as 
comodidades cultivando os campos, neles incutiu o amor ao ócio e à paz, aos quais muito facilmente se acrescentaram a justiça e a confiança, e com as quais se defende maximamente o cultivo dos campos e a colheita dos frutos. (De Rep. II, XIV, 26)

O regime econômico da cidade condiciona, e de alguma maneira outorga sustento, aos laços de proximidade tecidos entre os membros do corpo social. Tal é, aliás, a temática recuperada para a terceira e última contribuição de nossa coletânea por Thais Florencio de Aguiar. Mergulhando nas raízes profundas do vínculo comunitário, dos fundamentos da democracia grega que transmudam em pressupostos alternativos da democracia moderna, a interpretação adentra na noção de amizade ( philía) conceituada por Aristóteles nos livros VIII e IX da Ética Nicomaqueia. Mas, na visão ética do pensador nativo de Estagira, de jovem enviado a Atenas com o propósito de integrar-se à Academia platônica, a philía tem sua reconhecível tradução política e a política, enquanto ação teorizada e teoria da práxis, sua inegável especificidade. Na medida em que o governo político só é exercido entre homens livres e iguais, entre cidadãos que tomam parte do poder supremo e deliberativo da assembleia e do poder de julgar nos tribunais (Pol. 1255b16-20; 1275b17-20), faz-se concebível um tipo de relação não menos específica na qual se vislumbra a amizade política (politiké philía, cf. EN IX, 6, esp. 1267b2-4; Cooper, 1990), pedra angular da coesão entre as partes do todo e, portanto, da vida em comum:

É claro, pois, que a cidade não é uma comunidade de lugar e cujo fim seja evitar a injustiça mútua e facilitar o intercâmbio. Todas essas coisas se darão necessariamente, sem dúvida, se existe a cidade; mas o fato de que se deem todas elas não basta para que haja cidade, que é uma comunidade de casas e de famílias com o fim de viver bem, 
de conseguir uma vida perfeita e suficiente. Esta não poderá realizar-se, no entanto, sem que os cidadãos habitem um mesmo lugar e contraiam entre si matrimônios. Daqui surgiram nas cidades as alianças de famílias, as fratrias, os sacrifícios públicos e as diversões da vida em comum; e essas coisas são produto da amizade, já que a escolha da vida em comum supõe a amizade. (Pol. 1280b29-39.)

Contudo, os méritos da proposta de Aguiar não se limitam apenas a sua redescoberta aguçada do paradigma democrático das comunidades helenas, já que sua leitura pulsa, e especialmente invade com o laço "demofílico", o território vasto, porém encapsulado e algo ríspido, da atual teoria democrática, obrigada por causa de suas penúrias a repensar os usos da teoria política clássica, a empreender uma renovação que somente iniciará se percorrer o longo caminho de retorno a essa Ítaca que parece tão distante, através do qual o pensamento volta a conversar com os antigos e esse espelho lhe devolve algumas lições esquecidas.

Resulta disso a lição elementar aprendida, com algo de perplexidade, do dizer de um historiador que abstrai a polissemia elusiva dessa realidade múltipla: "a política não é uma coisa só” (Hammer, 2009, p. 34). Em meio a tudo o que um nome encadeia, damos afinal com o que se indagava no começo e neste encerramento poderíamos denominar equivalente mínimo da reflexão e do discurso político clássico: uma teoria da organização política das comunidades antigas, entendendo por tal uma reconstrução das formulações intelectuais relativa às formas de ordenação do poder entre cidadãos, à determinação específica da cidadania conforme critérios verticais e horizontais de gradual atribuição da igualdade e da liberdade, e às condições materiais e ideais da formação histórica dessas comunidades em suas dimensões prática, ideológica e institucional. Na densa trama das experiências das comunidades igualitárias, livres e participativas da Grécia e da Roma desse longo 
período, em suas constituições democrática e republicana e seus concretos vocabulários e conceitos, em definitiva, de sua singularidade, brotam também as traças de sua universalidade, possibilidade ocidental de um legado (cf. Balot, 2009b, pp. 4-6; Hammer, 2015, pp. 1-2). ${ }^{9}$ Não há melhor pretexto que esse para voltar a falar de tudo aquilo, para retornar àqueles autores, interpelando os mitos, o drama e a glória que nos contam, em respostas que serão ensaios de interpretação com muito de imaginário e conjectural. Apesar de que, desse passado remoto, desde então vertido em linhas e trajetórias ramificadas e mescladas num labirinto de tempos alvos da admiração e do desdém modernos, restem os feitos narrados e as palavras inscritas, já nem sequer como maravilhas e proezas, mas como fusões de textualidade, textos sobreviventes - cortados, copiados, modificados -, que deixamos aos vários (não a todos) modos de pensamento e ação do porvir.

\section{Patricio Tierno}

é professor de Teoria Política do Departamento de Ciência Política da Universidade de São Paulo.

\section{Bibliografia}

ARISTÓTELES. 2002. Ética a Nicómaco. Edición bilingüe y traducción de

María Araujo y Julián Marías. Introducción y notas de Julián Marías.

Madrid: Centro de Estudios Políticos y Constitucionales.

ARISTÓTELES. 1997. Política. Edición bilingüe y traducción de Julián

Marías y María Araújo. Introducción y notas de Julián Marías. Madrid:

Centro de Estudios Políticos y Constitucionales.

BALOT, Ryan K. (org.). 2009a. A companion to Greek and Roman political thought. Malden, MA: Wiley-Blackwell.

BALOT, R. K. 2009b. Introduction. In: BALOT, Ryan K. (org.). A

companion to Greek and Roman political thought. Malden, MA, Oxford, Chichester: Wiley-Blackwell. pp. 3-19.

9 Para uma série de considerações que resgatam noções do pensamento político antigo negligenciadas pela teoria contemporânea, vide Balot (2009b, pp. 13-15). 
BORGES, Jorge Luis. 1963. El jardín de senderos que se bifurcan. In: BORGES, Jorge Luis. Ficciones. Buenos Aires: Emecé. pp. 97-111. CICERO, Marcus Tullius. 1999. On the Commonwealth. In: ZETZEL, James E. G (ed.). On the Commonwealth and On the Laws. Cambridge: Cambridge University Press. pp. 1-104.

COOPER, John M. 1990. "Political Animals and Civic Friendship", with commentary of J. Annas. In: PATZIG, Günther (org.). Aristoteles' "Politik": Akten des XI Symposium Aristotelicum. Göttingen: Vandenhoeck \& Ruprecht. pp. 220-248.

EUBEN, J. Peter. 1986. Introduction. In: EUBEN, J. Peter (org.). Greek Tragedy and Political Theory. Berkeley: University of California Press. pp. 1-42.

FARENGA, Vincent. 2015. Liberty, Equality, and Authority: a Political Discourse in Greek Participatory Communities. In: HAMMER, Dean (org.). A companion to Greek Democracy and The Roman Republic. Malden, MA: Wiley-Blackwell. pp. 101-112.

GARGARELLA, Roberto. 1999. Las teorias de la justicia después de Rawls: un breve manual de filosofía política. Barcelona: Paidós.

HAMMER, Dean. 2015. Introduction. In: HAMMER, Dean (org.). A companion to Greek Democracy and The Roman Republic. Malden, MA: Wiley-Blackwell. pp. 1-7.

HAMMER, D. 2009. What is Politics in the Ancient World?. In: BALOT, Ryan K. (org.). A companion to Greek and Roman political thought. Malden, MA: Wiley-Blackwell. pp. 20-36.

KONSTAN, David. 2015. Reading the past (on comparison). In: HAMMER, Dean (org.). A companion to Greek Democracy and The Roman Republic. Malden, MA: Wiley-Blackwell. pp. 8-19.

MAQUIAVELLI, Niccolò. 1996. Discourses on Livy. Translated by Harvey C. Mansfield and Nathan Tarcov. Chicago: University of Chicago Press. MOURITSEN, Henrik. 2015. The incongruence of power: the Roman constitution in theory and practice. In: HAMMER, Dean (org.). A companion to Greek Democracy and The Roman Republic. Malden, MA: Wiley-Blackwell. pp. 146-163.

OBER, Josiah. 1999a. Introduction. In: OBER, Josiah. The Athenian Revolution: essays on Ancient Greek democracy and political theory. Princeton: Princeton University Press. pp. 3-12.

OBER, J. 1999b. Models and Paradigms in Ancient History. In: OBER, Josiah. The Athenian Revolution: essays on Ancient Greek democracy and political theory. Princeton: Princeton University Press. pp. 13-17. 
OBER, J. 1999c. Public Speech and the Power of the People in Democratic Athens. In: OBER, Josiah. The Athenian Revolution: essays on Ancient Greek democracy and political theory. Princeton: Princeton University Press. pp. 18-31.

OBER, J. 1999d. The Nature of Athenian Democracy. In: OBER, Josiah. The Athenian Revolution: essays on Ancient Greek democracy and political theory. Princeton: Princeton University Press. pp. 107-122. OBER, J. 1999e. How to criticize democracy in late fifth- and fourthcentury Athens. In: OBER, Josiah. The Athenian Revolution: essays on Ancient Greek democracy and political theory. Princeton: Princeton University Press. pp. 140-160.

OBER, J. 1998. Political dissent in democratic Athens: intellectual critics of popular rule. Princeton: Princeton University Press.

PERSEUS Digital Library. Medford: Tufts University, [2019]. Disponível em: www.perseus.tufts.edu/hopper. Acesso em: 16 ago. 2019.

PLATÓN. 1963. República. Traducción directa del griego por Antonio Camarero. Estudio preliminar y notas de Luis Farré. Buenos Aires: Eudeba.

RHODES, Peter John. 2015. The congruence of power: ruling and being ruled in Greek participatory communities. In: HAMMER, Dean (org.). A companion to Greek Democracy and The Roman Republic. Malden, MA: Wiley-Blackwell. pp. 131-145.

ROWE, Christopher. 2005. Introduction. In: ROWE, Christopher; SCHOFIELD, Malcom (org.). The Cambridge History of Greek and Roman political thought. Cambridge: Cambridge University Press. pp. 1-6. ROWE, Christopher; SCHOFIELD, Malcom (org.). 2005. The Cambridge History of Greek and Roman political thought. Cambridge: Cambridge University Press.

SCHOFIELD, Malcom. 2015. Liberty, equality, and authority: a political discourse in the later Roman Republic. In: HAMMER, Dean (org.). A companion to Greek Democracy and The Roman Republic. Malden, MA: Wiley-Blackwell, 2015. pp. 113-127.

THESAURUS Linguae Graecae: a digital library of greek literature. Irvine: University of California Irvine, 2014. Disponível em: www.tlg.uci.edu. Acesso em: 16 ago. 2019.

THUCYDIDES. 2009. The Peloponnesian War. Translated by Martin Hammond. With an Introduction and Notes by Peter John Rhodes. Oxford: Oxford University Press. 


\section{TEORIA POLÍTICA CLÁSSICA: RAMIFICAÇÕES DE GRÉCIA E ROMA}

\section{PATRICIO TIERNO}

Resumo: Apresenta-se aqui uma reflexão em torno do estatuto da teoria política clássica e dos modos constitutivos dessa mesma reflexão. Dessa perspectiva, é possível conceber a teoria política clássica como uma variada estrutura temática e argumentativa que abarca diversos gêneros e registros discursivos e cuja trama recorrente deve e pode ser reconstruída buscando apreender sua significação contextualizada e os sentidos de sua apropriação atual. Por fim, exemplifica-se essa operação de reconstrução e captação histórico-intelectual com os tópicos tratados pelos artigos que compõem o presente Dossiê.

Palavras-chave: Teoria Política Clássica; Grécia; Roma; Temporalidade; Reflexão.

\section{CLASSICAL POLITICAL THEORY: RAMIFICATIONS OF GREECE AND ROME}

Abstract: This introductory article proposes a reflection on the status of classical political theory and its constitutive modes of thought. From this perspective, classical political theory is conceived as a heterogeneous thematic and argumentative structure that encompass different genres and levels of discourse, which recurring framework can and ought to be reconstructed aiming to apprehend its contextual meaning and the meaningful relevance of its current appropriations. Finally, such historical and intellectual exercise is exemplified by the different topics that constituted the subject-matter of the articles presented in this monographic study.

Keywords: Classical Political Theory; Greece; Rome; Temporality; Reflection.

Recebido: 27/09/2018 Aprovado: 16/07/2019 